Brit. F. vener. Dis. (1969), 45, 254.

\title{
SEXUALLY ACQUIRED GONORRHOEAL URETHRITIS IN A 6-YEAR-OLD BOY*
}

\author{
BY \\ N. J. FIUMARA $†$ AND J. M. BRILEY, JR. $\ddagger$ \\ Boston City Hospital, Mass.
}

Gonorrhoea has the distinction of being not only the oldest, but also the most prevalent, of the venereal diseases. In the fiscal year 1968, 431,380 cases of gonorrhoea were reported in the United States, establishing a new record and displacing the previous high mark of 1947 when 405,350 cases were reported (USPHS, Personal Communication). There are about twenty cases of gonorrhoea reported to one case of infectious (primary and secondary) syphilis. Like syphilis, gonorrhoea is a disease of metropolitan centres, its greatest concentration being in the core cities and from there fanning out into the suburbs. There are five times more cases of gonorrhoea reported from urban than from rural areas.

Gonorrhoea is predominantly a disease of teenagers and young adults; those in the 20 to 24-year-old age group have the greatest incidence and account for about 36 per cent. of the total number of cases. Adolescents in the age group 15 to 19 rank second in frequency with 21 per cent. of the total cases, and older adults, those in the 25 to 29-year age group, follow in third place. Children under 10 years of age are seldom diagnosed as having gonorrhoea; cases in this age group comprise less than 0.5 per cent. of the total and the females reported outnumber the males by 3 to 1 .

In this paper we present a case of sexually acquired gonorrhoea in a 6-year-old boy, whom we believe is the youngest male with this disease so contracted ever to be reported in the medical literature.

\section{Case Report}

A 6-year-old boy was admitted to the Accident Floor of the Boston City Hospital on September 11, 1967, complaining of pain on urination which had persisted for 3 days. The mother had noticed that the boy had frequency of micturition and whimpered while urinating, so she brought him to the hospital. $\mathrm{He}$

*Received for publication February 21, 1969.

†Director, Division of Communicable Diseases, Massachusetts Department of Public Health; associate clinical professor of dermatology and preventive medicine, Boston University School of Medicine; lecturer in dermatology and syphilology, Tufts University School of Medicine; instructor in dermatology, Harvard Medical sity School; clinical associate in dermatology, Massachusetts Genera Hospital; visiting physician, University Hospital, associate physician for dermatology, Boston City Hospital; physician, Department of Dermatology and Syphilology, Boston Dispensary.

‡Pediatric Intern, Boston City Hospital. denied inserting anything into the urethra. There was no history of chills or fever, no pain in the back, no bloody discharge or haematuria, and no incontinence.

Examination.-There was a dirty yellow purulent urethral discharge and a Gram-stained smear revealed abundant Gram-negative intracellular diplococci.

The child was immediately admitted to the Paediatric Service, where except for the genital findings, physical examination revealed nothing abnormal. The penis was of normal size, he had not been circumcised, and from the urethral orifice a purulent discharge could be obtained with minimal pressure.

Diagnosis.-A specimen of pus was streaked on to Thayer-Martin VCN medium, and in 48 hours an oxidase-positive culture was obtained; sugar tubes were inoculated with the fermentation of dextrose, but not maltose and sucrose, thereby confirming the diagnosis. A blood test for syphilis was negative.

Treatment.-An injection of 1.2 million units procaine penicillin $G$ in aqueous suspension was followed by prompt clinical response.

Contact Tracing.-The patient was interviewed by one of our public health nurse epidemiologists who found that he had had sexual exposures with a 14-yearold and an 8-year-old girl. Both girls were located; both were found to be infected with gonorrhoea and were treated.

\section{Summary}

This 6-year-old boy is believed to be the youngest male with sexually acquired gonorrhoea to have been reported in the medical literature. The case is presented to draw the attention of physicians to the fact that gonorrhoea should be considered in the differential diagnosis of urethritis even in very young children.

\section{REFERENCE}

U.S. Public Health Service, Communicable Disease Center, Atlanta, Georgia. Personal communication.

\section{Urétrite gonococcique contractée sexuellement chez un garçon de 6 ans \\ RÉSUMÉ}

On pense que ce garçon de 6 ans, atteint de gonococcie d'origine sexuelle, est le plus jeune sujet mâle signalé dans la littérature médicale. Ce cas est rapporté pour attirer l'attention des médecins sur le fait que la gonococcie doit être envisagée dans le diagnostic des urétrites, même chez les très jeunes enfants. 